\title{
Indicators for the ecological planning of buildings
}

\author{
C. Seyler, C. Stoy, I. Lützelschwab \& S. Kytzia \\ Department of Civil, Environmental and Geomatic Engineering, \\ Swiss Federal Institute of Technology Zurich, Switzerland
}

\begin{abstract}
Until now, ecological assessments of buildings have been focussing on the use phase, such as the consumption of operating energy or the emission of in-house pollutants. So far, little emphasis has been placed on the construction and disposal phase of buildings. As the use phase is getting more and more optimised, environmental impacts caused by the construction phase are gaining in importance. To optimise the ecological performance of a building information is needed in the early design phases when there is still a wide scope for decision. This paper presents a method, based on cumulative energy indicators, which allows assessing the environmental impacts of a building when only a little information is known.
\end{abstract}

Keywords: life cycle, indicator, early design phase, building material, environmental impact assessment.

\section{Introduction}

In the last years the main focus of environmentally friendly buildings has been laying on the use phase. Large efforts have been put, e.g., on the optimisation of operation energy and the prevention of indoor pollutant emission. Those environmental impacts have become more and more optimised, e.g., by using better insulation, the use of energy saving machines or by the substitution of critical materials in housing spaces. As a result, the other phases in the building's life cycle, such as the construction phase or the disposal phase, have gained in importance. Recent LCA studies have clearly shown a shift of the main environmental impacts from the use phase towards the construction phase for 
ecologically optimised buildings [1]. Thus, to get further environmental improvements in a building's performance planners and architects should now concentrate on the construction phase.

To include the environmental impacts of the construction phase in the planning of a building several instruments have been developed in the Germanspeaking region in the last years, e.g. [2, 3, 4, 5]. Those instruments are used in different planning and design stages and they require information on different levels of detail. Of special interest are instruments which can be used in an early design phase as they allow for decisions at a stage when there is still a wide scope for decisions. Such instruments exist, but they usually work on a qualitative basis, e.g., on checklist or recommendations $[4,5]$. No method which allows for a quantitative assessment of the environmental impacts of buildings in early design stages exists today.

We have developed an instrument which can be used for a quantitative estimation of the environmental impacts of the construction phase of a building in early design stages. Our method works in analogue to the principle of quantitative cost estimation of buildings in early design phases [6, 7]. We provide indicators which base on the cumulative energy demand of the material composition of the building. Those indicators are derived from reference buildings and are listed in a reference building catalogue. To make an environmental assessment of a building, a reference building from the catalogue is chosen and the corresponding indicators are multiplied with reference quantities of the building under study such as the gross floor area or the gross volume. Cumulative energy demand as a measure for the environmental impact is chosen because it is known to architects and because it allows for a direct comparison with other energy consumptions of the building, e.g., the operating energy. In this paper we present how our cumulative energy indicators are calculated from reference buildings and how they are applied.

\section{Calculating the cumulative energy indicators}

\subsection{Method: from accounting documents to indicators}

The cumulative energy indicators are developed in analogue to economic indicators which are used for estimation of building construction costs in early design phases [6,7]. Figure 1 shows the proceeding for developing such indicators. The basis for calculating the indicators are accounting documents of already existing buildings. Those accounting documents, which contain information on the building process, the type and dimensions of the materials used and the arising costs, are evaluated systematically. First, every documented work is assigned to an element group according to the standard for cost calculation $[8,9]$. The standard for cost calculation classifies the costs of all works of a building into different cost groups. The classification bases on the different components and parts of a building (so-called element groups) and can be done on different levels. 
Eco-Architecture: Harmonisation between Architecture and Nature 229
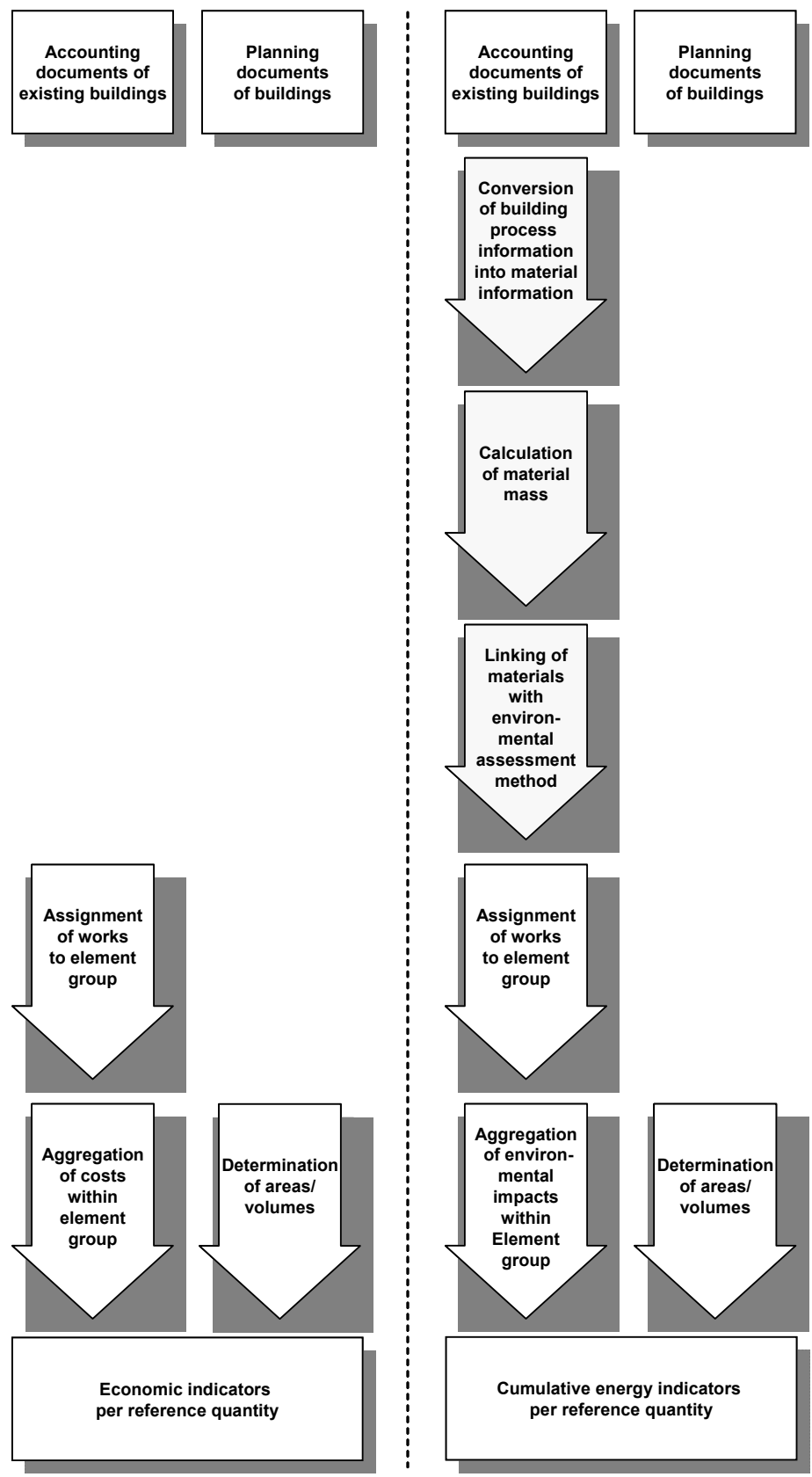

Economic indicators per reference quantity

Figure 1: $\quad$ Scheme of the proceeding for calculating economic indicators (left hand side) and ecological indicators (right hand side). 
For calculating the indicators, for example a work such as ,putting down and compressing of a gravel layer" would be assigned to the element group "foundations". In the next step, all arising costs (or environmental impacts for the ecological indicators) within one element group are summed up to yield the total costs per element group. Such an aggregation can be done on different building levels according to the standard for cost calculation. In parallel, the reference quantities such as areas or volumes of the element groups are determined from the planning documents [10]. Such reference quantities are, e.g., the external wall area or the excavation volume. In the last step the aggregated costs (or environmental impacts) are divided by their belonging reference quantity. The result is an indicator which indicates how much, e.g., $1 \mathrm{~m}^{2}$ of external wall area costs.

For calculating ecological indicators, the information from the accounting documents has first to be converted into ecological relevant information (see Figure 1, grey arrows on right hand side). This is done by first converting the information on the building process into information on the building material. E.g., information such as "putting down and compressing of a gravel layer" is converted into the material information "gravel". Or the building process information "installation of boarding panel with timber framework" is assigned to the material "wood". In the next step the mass of the materials is calculated. Usually enough information on the dimension of the building components can be found in the accounting documents. Together with the material density, which is taken from literature, the mass of the used material can be calculated.

When the material masses are known, they can be linked with an environmental impact assessment method. In principal, any assessment method can be chosen, e.g., the Eco-indicator 99 [11] or $\mathrm{CO}_{2}$-equivalents [12]. For the reason explained above, we chose the cumulative energy demand as assessment method [13]. Values for the specific cumulative energy demand for different building materials can be taken from literature or electronic databases. As our indicators have been calculated for Switzerland, values have been taken from Swiss literature [14]. By multiplying the material mass with its specific environmental impact, the total environmental impact of a building component can be calculated. Taking the gravel example from above and considering a surface of the gravel layer of $190 \mathrm{~m}^{2}$ and a thickness of $15 \mathrm{~cm}$, the mass amounts to $51300 \mathrm{~kg}$ (assuming a gravel density of $1800 \mathrm{~kg} / \mathrm{m}^{3}$ ). By liking the mass to the specific cumulative energy demand of gravel, which is $0.03 \mathrm{kWh} / \mathrm{kg}$, the cumulative energy demand of the gravel layer is calculated to be $1540 \mathrm{kWh}$.

Then, again, this ecological information is assigned to the element group according to the standard for cost calculation and aggregated within this element group. At the end, these aggregated values are divided by their belonging reference quantity. The results are cumulative energy indicators per, e.g., $\mathrm{m}^{2}$ of external wall area or $\mathrm{m}^{2}$ of gross floor area of the reference building.

\subsection{Results: cumulative energy indicators for 20 buildings}

Until now, 20 buildings have been evaluated and cumulative energy indicators have been calculated [15]. Two indicators are provided on the level of the overall 
building, one based on the gross floor area and one based on the gross volume of the building. A second set of indicators have been calculated on the level of socalled macro elements. On the macro level a building is divided into large element groups such as foundation, external walls, internal walls, floors and ceilings, roofs [8]. These are element groups which are very appropriate for the use of indicators as their approximate measures are known already in early design stages [1]. Note that the service installations have not been included in our survey although they usually have a large contribution to the ecological performance of a building. The indicators on the macro level refer to the reference quantity according to the standard for cost calculation, e.g., the external wall area [10]. In Figure 2 the cumulative energy indicators for two examples are shown.
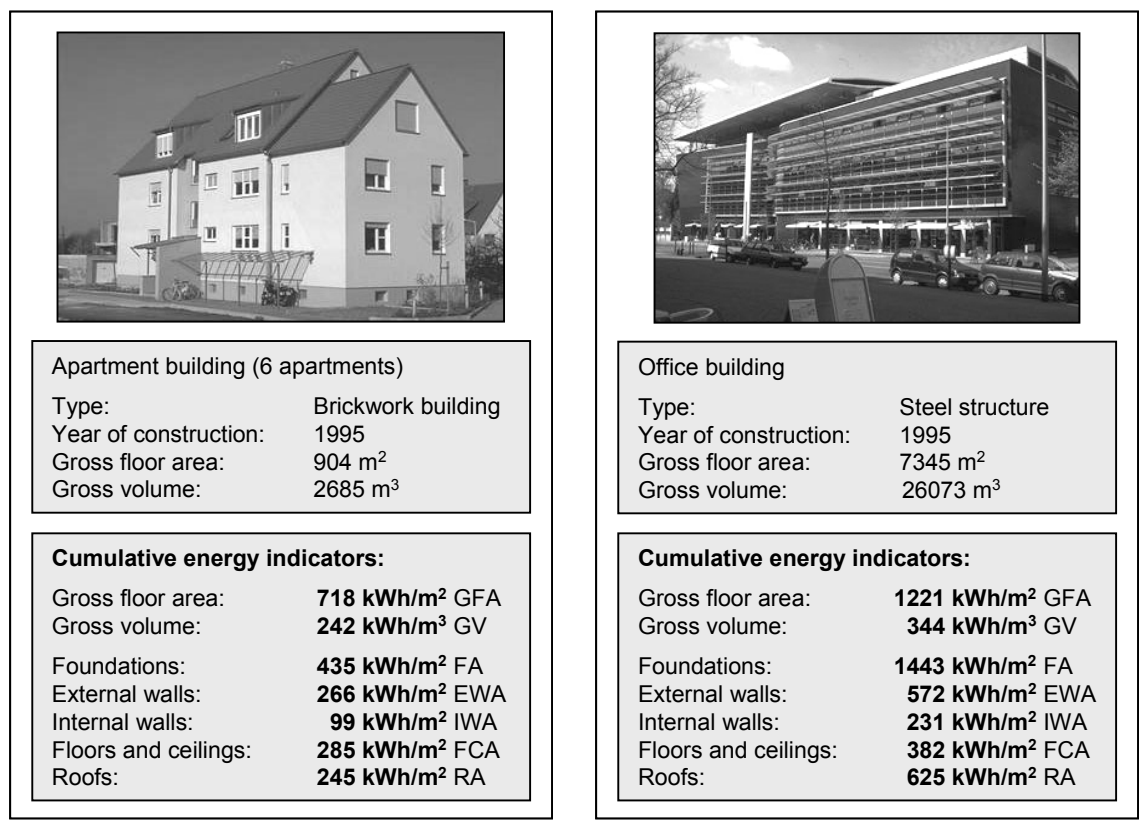

Figure 2: Cumulative energy indicators for an apartment building and an office building. GFA: Gross floor area of building, GV: Gross volume of building, FA: Area of foundation, EWA: External wall area, IWA: Internal wall area, FCA: Floor and ceiling area, RA: Roof area.

The first example is an apartment building constructed in brickwork. The house has a gross floor area of $904 \mathrm{~m}^{2}$ and a gross volume of $2685 \mathrm{~m}^{3}$. The calculated cumulative energy indicator based on the gross floor area amounts to $718 \mathrm{kWh} / \mathrm{m}^{2}$, the one basing on the gross volume amounts to $242 \mathrm{kWh} / \mathrm{m}^{2}$. Compared with the building on the right hand side, which is an office building in steel structure, it can be seen that the indicators for the apartment house are 
lower. This means that the specific environmental impact (per $\mathrm{m}^{2}$ gross floor area or $\mathrm{m}^{3}$ gross volume) is lower than for the office building. The second set of indicators is the one for the macro elements. For the apartment building it's the foundation which has the highest impact per reference area $\left(435 \mathrm{kWh} / \mathrm{m}^{2} \mathrm{FA}\right)$, the lowest specific impact comes from the internal walls ( $99 \mathrm{kWh} / \mathrm{m}^{2}$ IWA). Note that these values cannot be compared each other as they have a different reference quantity.

\section{Application of the cumulative energy indicators}

\subsection{Estimating the environmental impact of a building}

To estimate the environmental impact of a building at an early design stage first a reference building or a reference macro element has to be chosen from the reference building catalogue. In the reference building catalogue cumulative energy indicators for two building levels are listed: one on the overall building level and five on the macro element level. The choice of a suitable reference building bases on different aspects such as the function of a building (e.g. apartment house, warehouse, office building), the construction type (e.g. steelwork, brickwork, timber frame), the specific materials for building components (e.g. wooden or aluminium window frames) or the realisation standard of the building (average, high). In the second step, the dimensions of the planned building or macro elements are taken from the sketch. The environmental impact for the overall building is then calculated as follows:

$$
\text { Environmental impact }_{\text {building }}=\text { Area }\left(\text { Volume }_{\text {building }} * \text { Indicator }_{\text {building }}\right.
$$

or in the case of calculating a macro element:

$$
\text { Environmental impact } \text { macro element }=\text { Area }_{\text {macro element }} * \text { Indicator }_{\text {macro element }}
$$

The lower the resulting value, the lower is the environmental impact for the building under study. Note that a building which has a low cumulative energy indicator not necessarily has a low environmental impact. If the building has a large gross floor area it can even be worse than a comparable building with a higher cumulative energy indicator.

\subsection{Calculating a theoretical case study}

To illustrate the application of the cumulative energy indicators a theoretical case study is calculated. We assume that an architect plans to build a three family row house. Figure 3 shows a sketch of a model which is under discussion. The building is built in timber frame and the planned gross floor area amounts to $645 \mathrm{~m}^{2}$. For doing an early estimation on the ecological performance of the planned building the architect chooses a reference building from the reference building catalogue (see Figure 3 right hand side). 

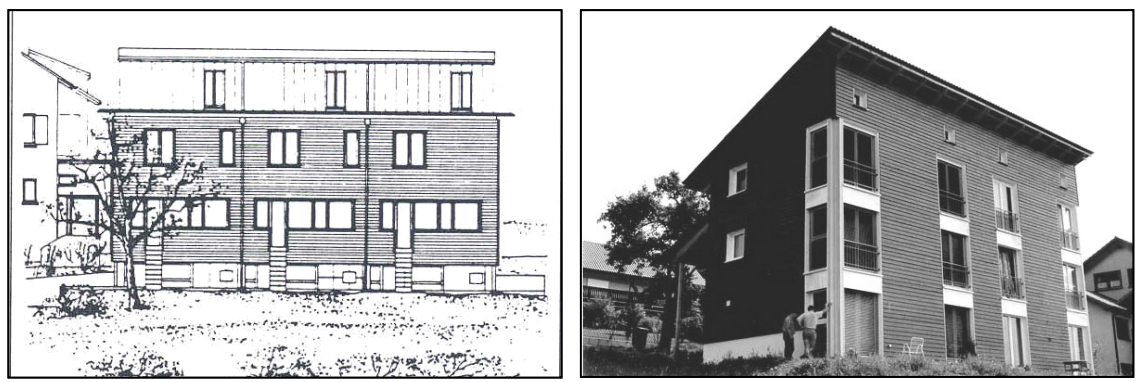

Figure 3: Sketch of a possible model for a three familiy row house in timber frame (left hand side) and a possible reference building from the reference building catalogue (right hand side).

The ecological indicator for the reference building is $769 \mathrm{kWh} / \mathrm{m}^{2}$ GFA. Thus, the environmental impact for the planned house results in $496000 \mathrm{kWh}$ cumulative energy demand. This value can now be used to benchmark, e.g., to compare the chosen model with instructions or reference values from the tender documents. The value can also be compared with values resulting from an evaluation of the energy consumption from the operating phase of the building. As the architect is still at a very early stage of the planning process he or she can easily adapt the sketch if necessary.

\subsection{Adapting the cumulative energy indicators to personal needs}

The ecological indicators can also be adapted to personal needs. The user might for example want to use another environmental impact assessment method instead of the cumulative energy demand. This is possible by linking the material masses of the reference buildings to another assessment method as described in section 2.1. There exists a variety of databases which allow a direct linking of building materials with their environmental impacts, such as e.g. GEMIS in Germany [16] or Ecoinvent in Switzerland [17]. The environmental impacts of materials and energies can show great variations depending on their production location (example: aluminium production with hydro power versus production with fossil fuels). Therefore, it is important to consider the geographical region where the building under study is located and use a database which covers the region.

Another aspect which the architect might want to integrate into his or her calculation is the different life span of the building components. When the whole life cycle of a building is looked at one has to take into account that there usually is a replacement of different building components. For example windows and window frames are normally replaced several times during the life span of a building. To integrate the environmental impacts caused by the replacement of building components new material masses can be calculated by considering the life span. The new material mass (also called life time mass [1]) is calculated by multiplying the mass with the factor lifetime building $_{\text {lifetime }}$ material. The cumulative energy indicators are then re-calculated considering the new mass. 


\subsection{Quality of the results}

For the interpretation of the results obtained by using cumulative energy indicators an uncertainty discussion is recommended. Such an uncertainty discussion, which can be qualitative or quantitative, should be done by identifying and weighing all uncertain information encountered during the calculation and application of the indicators. Only by carrying out such a discussion the user can draw sound conclusions on the results.

Uncertainties which arise during the calculation of the cumulative energy indicators should be estimated by experts. Such an uncertainty analysis should comprise aspects on both model uncertainty and data uncertainty [18]. Till now, we have made an identification of uncertainties in the different steps conducted for calculating cumulative energy indicators. The results are shown in Table 1. A first estimation on the grade of the uncertainty is given and can be used for a qualitative assessment.

Table 1: $\quad$ Source of uncertainty and grade of uncertainty for different steps in the calculation process of the cumulative energy indicators.

\begin{tabular}{|c|c|}
\hline Source of uncertainty & Grade of uncertainty \\
\hline $\begin{array}{l}\text { Determination of materials } \\
\text { - Conversion of building process information into } \\
\text { material information } \\
\text { - Calculation of material mass } \\
\text { - Linking of materials with environmental impact } \\
\text { assessment method }\end{array}$ & $\begin{array}{l}\text { medium } \\
\text { low } \\
\text { medium }\end{array}$ \\
\hline $\begin{array}{l}\text { Environmental impact assessment method } \\
\text { - } \text { System boarders of process chains } \\
\text { - Data survey for material production }\end{array}$ & $\begin{array}{c}\text { medium } \\
\text { medium - high }\end{array}$ \\
\hline $\begin{array}{l}\text { Determination of indicators } \\
\text { - Determination of reference quantities }\end{array}$ & low \\
\hline
\end{tabular}

Three sources of uncertainty have been identified for the determination of materials from the accounting documents. First there can be an uncertainty when assigning the building process information to one material, e.g. a door can consist of both wood and glass. Second, when calculating the material mass there can be a lack of clarity on the dimensions of a component. And third, there might be "non-fittings" between the material used in the building and the material list of the environmental assessment method, e.g. there might not be the same type of concrete. There are further uncertainties which come from the use of an environmental impact assessment method. Those uncertainties, which sometimes can be quite large, include e.g. the data survey for the production of the building material and the system boarders which are chosen for the production process chain. For further information on this subject the reader is referred to literature, e.g., [18]. A lower grade of uncertainty comes from the determination of the reference quantities from the planning documents. 
For a quantitative uncertainty analysis the grade of uncertainty must be quantified. This would then allow calculating an uncertainty range on the cumulative energy indicators by using quantitative assessment methods such as e.g. Monte Carlo simulation.

Uncertainties during the application of the cumulative energy indicators arise especially from the choice of a suitable reference building. This drawback can be overcome by using different similar reference buildings in the sense of a sensitivity analysis. A clear improvement will be reached when the selection of buildings is extended by enlarging the catalogue of reference buildings.

\section{Discussion and outlook}

We have shown that an estimation of environmental impacts of buildings is possible already at an early design phase. The presented cumulative energy indicators can be used for a quick estimation at a planning stage where there is only rough information on the dimension of the building and the used materials. The result can then be compared with other buildings or with a reference value laid down by the client. If the result does not satisfy the needs, the sketch can be adapted or different materials can be chosen. Such changes can be done easily because the information on the environmental impact is available at a very early design stage. The indicators presented in this paper refer to the building construction only. Service installations are not included in our survey. However, as service installations usually have a significant contribution to the environmental impact of a building they should be looked at separately.

Today, the database on reference buildings comprises 20 buildings. This is a beginning but to get a use of the cumulative energy indicators as wide spread as the use of economic indicators the reference building catalogue has to be enlarged. This will be one of our main efforts. For this purpose we have access to the building database from the Baukosteninformationszentrum Deutscher Architektenkammern containing the accounting information of more than 1000 buildings. Nevertheless, although the principle of calculating the indicators follows a simple procedure, the work is time consuming. An electronic evaluation of the database will therefore be evaluated.

Another focus of our future work will be put on the uncertainty analysis. For a sound application of the developed indicators statements on the quality of the results are imperative. The aim is to provide cumulative energy indicators with an uncertainty range. Therefore, the next step will be to continue the uncertainty analysis by quantifying the grades of uncertainties which until now have been described qualitatively. Then the indicators are re-calculated integrating the ranges of uncertainty for every uncertainty source.

\section{References}

[1] Lalive d'Epinay, A., Die Umweltverträglichkeit als eine Determinante des architektonischen Entwurfs, Doctoral Thesis No. 13610 at the Swiss Federal Institute of Technology, Zürich, 2000. 
[2] OGIP, Optimierung der Gesamtanforderungen (Kosten/Energie/Umwelt) - ein Instrument für die integrale Planung, http://www.ogip.ch.

[3] Vitruvius, Vitruvius - Das Kostenplanungs-, Bewertungs- und Immobilienanalysesystem. http://www.vitruvius.ch.

[4] SIA D 0123, Hochbaukonstruktionen nach ökologischen Gesichtspunkten, Schweizer Ingenieur- und Architekten-Verein: Zürich, 1995.

[5] SNARC, Systematik zu Beurteilung der Nachhaltigkeit von Architekturprojekten für den Bereich Umwelt, sia-Dokumentation D 0200, Schweizer Ingenieur- und Architekten-Verein: Zürich, 2004.

[6] BKI Baukosteninformationszentrum Deutscher Architektenkammern, BKI Objekte - Kosten abgerechneter Bauwerke, BKI: Stuttgart, 1998.

[7] CRB Schweizerische Zentralstelle für Baurationalisierung, Baukostenkennwerte-Katalog BKK, CRB: Zürich, 1995.

[8] DIN-Norm, DIN 276 Kosten im Hochbau, DIN Deutsches Institut für Normung e.V. 1993.

[9] CRB Schweizerische Zentralstelle für Baurationalisierung, Kostenplanung mit der Elementmethode - Hochbau, CRB: Zürich, 1995.

[10] DIN-Norm, DIN 277-3 Grundflächen und Rauminhalte von Bauwerken im Hochbau, Teil 3: Mengen und Bezugseinheiten, DIN Deutsches Institut für Normung e.V. 1998.

[11] Goedkoop, M. \& Spriensma, R., The Eco-Indicator 99 - A damage oriented method for life cycle assessment: Methodology report, Pré Consultants bv: Amersfoort, 1999.

[12] IPCC Intergovernmental Panel on climate change, http://www.ipcc.ch.

[13] VDI Verein Deutscher Ingenieure, Kumulierter Energieaufwand Begriffe, Definitionen, Berechnungsmethoden, VDI, 1997.

[14] Kasser, U. \& Pöll, M., Graue Energie von Baustoffen - Daten zu Baustoffen, Bauchemikalien, Verarbeitungs- und Transportprozessen mit Erläuterungen und Empfehlungen für die Baupraxis, 2nd edition. Econum: St. Gallen, 1998.

[15] Kytzia, S., Seyler, C., Stoy, C., Lützelschwab, I., Primary energy indicators for the environmental assessment of buildings. In preparation.

[16] GEMIS, Globales Emissions-Modell integrierter Systeme. Öko-Institut e.V., http://www.oeko.de/service/gemis/de/index.htm.

[17] Ecoinvent, ecoinvent 2000, Swiss Centre for Life Cycle Inventories, http://ecoinvent.ch.

[18] Huijbregts, M.A.J., Application of Uncertainty and Variability in LCA A General Framework for the Analysis of Uncertainty and Variability in Life Cycle Assessment. International journal of Life Cycle Assessment, 3(1), pp.36-42, 1998. 